\title{
I. EL FRUSTRADO INTENTO DE REFORMA DE LA CONSTITUCIÓN DE LA PROVINCIA DE BUENOS AIRES
}

\author{
DANIEL A. SABSAY \\ y \\ ROBERTO P. SABA \\ Universidad de Buenos Aires
}





\title{
1. EL FRUSTRADO INTENTO DE REFORMA DE LA CONSTITUCIÓN DE LA PROVINCIA DE BUENOS AIRES
}

\author{
POR \\ DANIEL A. SABSAY * \\ y \\ ROBERTO P. SABA **
}

INTRODUCCIÓN

El reciente intento de reforma de la Constitución de la provincia más importante de la Argentina, por su población y concentración de riqueza, suscitó un trascendente debate en la sociedad que redundó en consecuencias políticas de primera magnitud para la nueva democracia. Este trabajo se propone analizar el fenómeno en sus connotaciones jurídicas y politicas, ya que la suerte corrida por el proyecto de ley fundamental para Buenos Aires permite elaborar interesantes conclusiones en relación con la fisonomía que va tomando el sistema luego de una transición que ya ha sufrido la prueba de la alternancia en el ejercicio del gobierno.

El federalismo es la forma de descentralización territorial del poder que ha adoptado la Constitución argentina de 1853. El artículo 104 de la Constitución Nacional establece que "las provincias conservan todo el poder no delegado por esta Constitución al gobierno federal...". Entre las facultades retenidas por las provincias se encuentra la de dictar sus propias Constituciones, dentro de los límites que les impone el artículo $5{ }^{\circ}{ }^{1}$. Ello a

* Profesor de Derecho Constitucional y de Derecho Político. Universidad de Buenos Aires.

** Asistente docente de Derecho Constitucional. Universidad de Buenos Aires.

Artículo 5. (Constitución de la República Argentina): "Cada provincia dictará para sí una Constitución bajo el sistema representativo republicano, de acuerdo con los principios, declaraciones y garantías de la Constitución Nacional; y que asegure su Administración de Justicia, su régimen municipal y la educación primaria...». 
efectos de asegurar la armonía entre un poder constituyente nacional o primario y tantos poderes constituyentes secundarios como provincias existan.

La restauración democrática argentiná de 1983 concitó una importante aspiración reformista a nivel constitucional. Tanto el Presidente Alfonsín como en la actualidad el Presidente Menem se propusieron modificar - hasta ahora sin éxito- la Carta Magna hacional. En cambio, desde las provincias, a partir de 1985 ha surgido un nuevo ciclo constituyente que se ha visto coronado con la reforma de nueve Constituciones provinciales. Los anteriores ciclos constituyentes provinciales ocurridos después de la sanción de la Constitución Nacional se suscitarón, o bien a raíz de la necesidad que tuvieron las provincias de darse sus primeras Constituciones, o bien como resultado de una adecuación a las reformas experimentadas en la Constitución Nacional. El ciclo iniciado en 1985 se diferencia sustancialmente de los anteriores ya que surgió de una auténtica necesidad de transformación de sus propias instituciones experimentada por las mismas provincias $^{2}$.

Esta necesidad obedeció al deseo de adecuar los antiguos textos a las nuevas realidades producto del desarrollo de la tecnologia, la transformación de las actividades, el cambio de los roles gubernamentales, entre otros aspectos que no habian sido previstos en las Constituciones precedentes. Las nuevas Constituciones han redundado en significativos aportes al Derecho público provincial argentino, ya sea incorporando derechos e instituciones o dándoles un tratamiento más acorde con los tiempos que corren.

Los cambios más importantes, muchos de ellos comunes a todas las nuevas Constituciones ${ }^{3}$, son los siguientes:

- Adopción del modelo de Estado Social de Derecho, lo que significa, un apartamiento del molde clásico de la Constitución Naciónal ${ }^{4}$. Ello a través de fórmulas que toman como principal antecedente al artículo $1^{\circ}$ de la Constitución española de 1978.

2 Vale aclarar que después del golpe de Estado de 1955, y una vez reimplantada la Constitución de 1853, volvieron a cobrar vigencia las Constituciones provinciales anteriores a 1949.

3. Cfr. el análisis de siete nuevas Constituciones provinciales efectuado por Daniel A. SABSAY en: «Algunos aspectos de las nuevas Constituciones provinciales argentinas", trabajo realizado a petición de la Universidad de Heidelberg y que se encuentra en trámite de publicación.

4 La Constitución Nacional argentina es representativa del denominado constitucionalismo clásico; sin embargo es preciso señalar que a partir de 1957, como consecuencia de una reforma, se incorpora el artículo 14 bis, que contiene un catálogo de derechos sociales. 
- Amplios catálogos de derechos sociales y aumento de las garantías para la protección de todas las libertades.

- Límites al ejercicio de los derechos, entre los que se destaca la noción de función social.

- Vigorizamiento de los controles de la actividad administrativa.

- Agilización del procedimiento para la formación y sanción de las leyes.

- Mayor vinculación entre los poderes Legislativo y Ejecutivo y un crecimiento de las facultades de este último.

- Descentralización territorial más genuina con el fortalecimiento de la autonomía municipal, y en algunos casos con la incorporación de la región como nuevo nivel de gobierno.

A nuestro criterio, todo este proceso ha sido encarado tomando como punto de partida la fuerza todopoderosa de la Ley. Sin embargo, pensamos que no por el hecho de que se logren plasmar en los textos numerosos y legítimos derechos, ello importará su inmediata puesta en vigencia. En la situación por la que atraviesan países como el nuestro, estas normas sólo constituyen un marco jurídico necesario pero no suficiente, para la real concreción de determinados ideales.

El fallido intento de modificación de la Constitución de la provincia de Buenos Aires se inscribía dentro del nuevo ciclo constituyente provincial a que estamos haciendo referencia. El proyecto retomaba y, en algunos casos, acentuaba muchos de los tópicos que señalamos más arriba y de haber sido aprobado se hubiera convertido en un hito de especial significación dada la relevancia demográfica, política y económica de Buenos Aires ${ }^{5}$. Nos proponemos exponer sobre las falencias de la Constitución bonäerense de 1934, tanto respecto de su legitimidad de origen como de su articulado, para luego referirnos al procedimiento empleado para su reforma, así como al contenido de la misma. Por último, esbozaremos un análisis de las causas y posibles consecuencias de los hechos que dieron por resultado el fracaso del intento de reforma.

5 En la provincia de Buenos Aires se encuentra el 40 por 100 de la población total del país, según los datos existentes en 1983. En el periodo 1978-1982, la provincia de Buenos Aires contribuyó con un 35,6 por 100 del PBI nacional. La importancia del PBI del sector industrial provincial en el PBI industrial nacional fue del 66 por 100 y el del sector agropecuario del 38 por 100. 


\section{LA CONSTITUCIÓN DE 1934}

El proceso que culminó con la sanción de la Constitución bonaerense vigente adoleció de una serie de incidentes y falencias que la hicieron muy deficitaria en lo relativo a su legitimidad ${ }^{6}$. En 1930 el Gobierno de Hipólito Yrigoyen, perteneciente a la Unión Civica Radical, fue desalojado del poder por un golpe de Estado. En 1931 se convocó a elecciones en la provincia resultando vencedor el mismo partido radical que poco antes habia sido removido del gobierno de la Nación, seguido en ese orden por conservadores y socialistas. El gobierno nacional de facto, ante tales resultados, anuló los comicios por decreto.

La nueva Legislatura sancionó la ley de necesidad de la reforma de la Constitución de resultas de la cual tuvo lugar una nueva elección para representantes ante la Convención Constituyente que se abocaría a la reforma. El radicalismo se abstuvo de participar en los comicios. La Convención, que quedó integrada por 106 miembros del Partido Demócrata Nacional (aliado del gobierno de facto) y 20 socialistas, se reunió del 27 de septiembre al 29 de noviembre de 1934. El 22 de noviembre se retiraron los socialistas en desacuerdo por la instauración de la enseñanza de la moral cristiana en las escuelas.

La falta de legitimidad democrática del procedimiento empleado para la gestión de la Constitución de 1934, caracterizado por la proscripción del partido mayoritario, resulta evidente. Pero además de tratarse de una Constitución impuesta por un sector que eludió toda concertación, gran parte de su normativa ha quedado obsoleta para los tiempos en que vivimos. Al margen de adherir a un constitucionalismo clásico desfasado con la realidad contemporánea, no prevé, o recepta en forma incompleta, numerosas cuestiones que exigen un nuevo tratamiento. Al respecto, creemos que cabe destacar la libertad de expresión, la libertad de conciencia, el derecho a la información, el rol del Estado en la promoción de la igualdad de oportunidades, el habeas corpus, el amparo, el derecho al trabajo, la protección del trabajador, del medio ambiente y la legitimación activa de todo habitante para su defensa, entre otros numerosos temas. Asimismo, en la parte orgánica de la Constitución, el procedimiento para la formación y sanción de las leyes es poco ágil, no resultan suficientes los mecanismos de control de la Administración y el Poder Judicial no se adapta, en muchos casos, a las características actuales de la sociedad provincial. El municipio carece de una auténtica autonomía lo que dificulta la descentralización territorial

- Ver Pablo Gabriel TONELli: «La Constitución de la provincia de Buenos Aires de 1934", El Derecho, tomo III, 1985, pp. 853-856, Buenos Aires. 
del poder en una provincia con un territorio tan extenso, como es el caso de Buenos Aires.

\section{LA REFORMA DE LA CONSTITUCIÓN BONAERENSE}

\section{El procedimiento elegido}

El artículo 192 de la Constitución bonaerense ${ }^{7}$ determina, que luego de aprobada por dos tercios del total de miembros de ambas Cámaras, la Ley que contendrá el proyecto de reforma y su alcance deberá también establecer si ha de convocarse o no a una Convención reformadora. De este modo la Legislatura puede optar entre dos alternativas procedimentales:

a) Qúe se convoque a una Convención Constituyente elegida por sufragio popular;

b) que la Ley que contiene la enmienda proyectada sea sometida a consulta de la población a través de un plebiscito que deberá tener lugar en la primera elección que se realice.

En esta oportunidad la legislatura optó por el segundo procedimiento. Otras Constituciones provinciales también han adoptado esta mecánica para su reforma, pero en esos otros casos, ella presenta una importante diferencia con relación a la Constitución bonaerense. Considerando como

7 Artículo 192 (Constitución de Buenos Aires): «Esta Constitución sólo podrá ser reformada por el siguiente procedimiento:

a) El proyecto de reforma será tramitado en la forma establecida para la sanción de las leyes, debiendo contar con el voto afirmativo de dos tercios del total de los miembros de ambas Cámaras para ser aprobado. La Ley indicará si la reforma será total o parcial y, en este último caso, las partes o los artículos que serán reformados.

b) La misma Ley establecerá si ha de convocarse o no a una Convención reformadora. En este último caso contendrá la enmienda proyectada y ésta será sometida a plebliscito en la primera elección que se realice. El voto será expresado en pro o en contra de la enmienda y su resultado será comunicado por la Junta Electoral al Poder Legislativo y a la Legislatura, para su cumplimiento.» 
ejemplo a las Constituciones de Neuquén y del Chubut ${ }^{8}$, ambas hacen la distinción entre la reforma global "que afecta al espíritu de la Constitución" y la modificación de pocos artículos. Para el primer caso prescriben la necesidad de que la reforma sea implementada por una Convención, mientras que para el segundo prevén la realización de un plebiscito para que la ciudadanía se pronuncie a favor o en contra de la enmienda que ya ha sido llevada a cabo por la legislatura. Esta distinción no ha sido contemplada por el constituyente de la provincia de Buenos Aires.

De todos modos la norma que comentamos se presta a distintas interpretaciones. La utilización del término «enmienda» en lugar de «reforma", permite que a ambas se les dé un significado diferenciado con el sentido que le otorgan las Constituciones mencionadas. Tal la posición asumida por muchos políticos y doctrinarios para tildar de inconstitucional el procedimiento elegido por el legislador bonaerense, dado que se trataba de una modificación que comprendía nada menos que 98 artículos sobre un total de 195. Sin embargo los defensores de esta postura parecieran olvidar que el texto constitucional no efectúa tal distinción y que toda interpretación basada en una aparente analogía con otras leyes fundamentales de provincia, importa querer hacerle decir a la Constitución lo que ella no ha dispuesto. Así lo ha entendido una parte importante de la doctrina ${ }^{\mathrm{g}}$.

Una segunda dificultad proviene de la interpretación de la expresión «primera elección» que contiene el citado artículo. Evidentemente el constituyente aspiró, inspirado en razones de mejor economia, a que no se convocara al electorado exclusivamente con la finalidad de plebiscitar la enmienda, sino que se aprovechara para ello una elección futura encaminada a la designación de autoridades. No obstante ello la Legislatura no lo entendió así, ya que procedió a realizar una convocatoria especial del electorado para que éste se pronunciara exclusivamente sobre la reforma proyectada. Pensamos que detrás de esta decisión pesaron motivos de orden político. El gobernador de la provincia, importante inspirador de la enmienda, presumiblemente aspiraba a que quedara incorporada a la nueva Constitución la posibilidad de reelección del titular del Poder Ejecutivo provincial. De haberse aprobado la reforma le quedaba expedito el camino para presentar su candidatura en los comicios de 1991. Oportunidad en la que, de haberse respetado la cláusula constitucional, debería haber tenido

but).

8 Artículo 300 (Constitución de Neuquén) y artículo 249 (Constitución de Chu-

9 Jorge R. A. VANOSSı ha dicho al respecto que «quizá el mecanismo elegido para la reforma no es el más conveniente y hubiese sido preferible recurrir a una Convención Constituyente, pero de ninguna manera se le puede tildar de inconstitucional». Además sostuvo que el artículo 192 «deja abierto un marco de posibilidades" en lo que se refiere al procedimiento de reforma, cuya elección queda a cargo del Poder Legislativo provincial» (La Nación, 5 de agosto de 1990, p. 7). 
lugar el plebiscito. Claro que de haber sido este último el proceder escogido, el actual gobernador no hubiese podido presentar su candidatura, pues la Constitución actual no admite su reelección. Razón por la cual el actual ocupante del Ejecutivo provincial y sus seguidores creyeron conveniente adelantar el pronunciamiento del electorado.

A nuestro criterio, si bien es cierto que una interpretación cuidadosa del articulado no permitía el adelantamiento de los comicios, el resultado que se ha conseguido de algún modo justifica la inobservancia. Ello en razón de que pensamos que, de haberse sometido tamaña reforma conjuntamente con la elección de autoridades provinciales y municipales, se hubiese tornado por demás dificultosa la decisión de los sufragantes, quienes seguramente hubiesen privilegiado la elección de las personas por sobre los aspectos relacionados con la Constitución.

\section{Contenido de la reforma}

La adopción de la variante social del constitucionalismo, constituía una de las notas más características del proyecto. El artículo $1 .^{\circ}$ decía que la provincia "constituye un Estado social y democrático de derecho" y que los «principios del pluralismo político, la participación popular, la solidaridad y la justicia social», son los que rigen al Estado.

Derechos, libertades y garantías

Al respecto el proyecto contenía cambios de gran importancia:

- Reconocía no sólo la libertad religiosa sino que la extendía incorporando la de conciencia, con lo que el ámbito de autonomía y tolerancia se veia significativamente más protegido ${ }^{10}$.

- Adoptaba una clara posición antidiscriminatoria y le otorgaba a la provincia el deber de «promover el pleno desarrollo de la persona humana, la igualdad de oportunidades y la efectiva participación de todos...",

10 Sin embargo, esta evolución normativa no se veía acompañada de la reforma del artículo $6 .^{\circ}$, que reconoce el «derecho que todo hombre tiene para rendir culto a Dios Todopoderoso, libre y públicamente...". Por lo tanto, no se amparaba la posibilidad de no rendir culto a ningún dios, lo cual no se condice con la libertad de conciencia, dado lo cual estimamos que se trata de una omisión importante de la Legislatura. 
con lo que el Estado asumía un rol activo en lo que se refiere a hacer efectivamente posible la vigencia de los derechos que se amparaban.

- Se preveía el derecho a la intimidad y a la vida «desde la concepción", prohibiendo de este modo el aborto.

- Reformulaba el contenido de la libertad de prensa, incluyendo el derecho a la información que tienen todos los miembros de la comunidad.

- Ampliaba el habeas corpus permitiendo una acción más rápida y eficaz. También establecía el amparo, instituto que no se encontraba previsto en el antiguo texto.

- Instituía al trabajo como derecho y deber social, obligando a la provincia a asegurar el goce de los derechos reconocidos al trabajador, asi como el cumplimieto de las obligaciones de los empleadores y la protección de la mujer y del niño. Imponía igualmente la oralidad del juicio laboral, lo que hubiera hecho más expeditiva su tramitación.

- Manifestaba que la actividad económica y el capital debian estar al servicio del hombre y cumplir una función social, siendo esta última el limite de la inviolabilidad de la propiedad privada.

- Le otorgaba al Estado la facultad de orientar las actividades económicas, por medio de la elaboración de los planes que debían contar con la participación de los sectores sociales y económicos.

- El artículo 28 consagraba los derechos sociales por primera vez en el constitucionalismo provincial bonaerense. En este sentido instituía a la familia como núcleo fundamental de la sociedad, comprometiendo al Estado a proteger la maternidad, la infancia, la juventud y la ancianidad; consideraba los problemas de las personas discapacitadas, la organización de un sistema de seguridad social; la vivienda, el derecho a la salud, la educación y el deber de la provincia de promover la investigación científica y tecnológica.

- Por primera vez en esta provincia se establecía el derecho a vivir en un medio ambiente adecuado para el desarrollo de la persona y el deber de conservarlo, así como la legitimación activa de todo habitante para accionar en defensa de aquel derecho.

- Reconocía a las asociaciones intermedias. Surgía como otra novedad la proscripción de los gobiernos ilegítmios y, a su vez, se declaraban inhabilitados a perpetuidad para ejercer cargos públicos aquellos que se hubieren alzado contra las autoridades legítimas. 
- Se instauraban las formas de democracia semidirecta y el sufragio quedaba reconocido como un derecho de los habitantes.

- Reconocia y garantizaba la existencia de los partidos políticos, como un instrumento fundamental para la participación y la intermediación políticas.

- Adoptaba, al igual que la Constitución vigente, la representación proporcional como sistema electoral para la integración de los órganos colegiados.

\section{Poder Legislativo}

- Disponía que los electores gozaran de la iniciativa en materia legislativa, gracias a la cual éstos podian presentar proyectos en la Legislatura.

- Establecía una mayoría cualificada de dos tercios del total de los miembros de cada una de las Cámaras, para la aprobación de leyes sobre régimen electoral y municipal, número de miembros de la Suprema Corte de Justicia ${ }^{11}$ y Ley Orgánica de la Fiscalía de Estado.

- Se preveía la posibilidad de que el Poder Ejecutivo enviara a la Legislatura proyectos de ley "con pedido de urgente tratamiento", es decir, con un plazo de treinta días para su consideración por cada Cámara, así como la fijación de plazos para que el Senado se pronunciara sobre los acuerdos para la designación de cierto tipo de altos funcionarios del Estado.

Justicia

El Poder Judicial conquistaba una mayor independencia a través del reconocimiento de una suerte de autarquía financiera en el cálculo de recursos, gastos e inversiones por parte de la Corte Suprema y también gra-

11 La previsión cobra en la actualidad una importancia particular en relación con el Poder Judicial, a la luz de lo ocurrido a nivel nacional. En el corriente año se sancionó, a instancia del Poder Ejecutivo, la Ley número 23774, por la cual se amplió el número de miembros de la Suprema Corte de Justicia de la Nación de cinco a nueve. Si bien se hizo uso de una potestad constitucional, de todos modos la nueva norma sirvió para teñir al máximo órgano de la Administración Nacional de Justicia con un tinte político cercano al del Presidente de la República. 
cias a la mayoria legislativa que se imponia para el cambio de la cantidad de sus integrantes. Se prevía la organización de la policía judicial que se integraria al Poder Judicial y se organizaba el Ministerio Público a cargo del Procurador General.

\section{Régimen municipal}

El Municipio adquiría en la proyectada reforma una dimensión totalmente distinta a la que posee en la Constitución de 1934. Se le reconocía como «una comunidad natural dotada de autonomía institucional, política, económico-financiera, tributaria y administrativa", a la que se le concedia la facultad de dictar su propia carta orgánica, a través de una convención municipal convocada especialmente a esos efectos.

Se ampliaban considerablemente las competencia y los recursos municipales y se limitaba la intervención provincial a las comunas. Todas medidas tendentes a confirmar en la práctica las virtualidades de la autonomía municipal y a hacer posible una genuina descentralización territorial del poder a nivel provincial.

\section{Reforma constitucional}

Se modificaban aquellos elementos que tornaban confuso o ambiguo el procedimiento para la reforma, de acuerdo a lo que analizamos en el punto anterior de este trabajo.

En relación con la oportunidad en que se debia convocar a plebiscito, se decidió cambiar la expresión: “primera elección que se realice», por "plazo máximo de ciento ochenta días", lo que permitiría evitar los inconvenientes que podía acarrear en el futuro una lejana "próxima elección" para proceder a la reforma de la Constitución a través de su ratificación plebiscitaria.

Poder Ejecutivo y control de la Administración

Las principales reformas que a nivel del Poder Ejecutivo habia elaborado el legislador, consistían, en primer término, en la posibilidad de reelección inmediata y por un solo periodo, del gobernador y del vicegobernador. En segundo término se incorporaba un interesante mecanismo de control de la Administración, que era ejercido por el Tribunal de Cuentas, quien debia informar anualmente a la Legislatura sobre el resultado de la cuenta general del ejercicio. 


\section{MARCO POLÍTICO}

El análisis que realizamos de lo acontecido con el intento de reforma de la Constitución bonaerense no se limitará exclusivamente a su faz jurídica. Creemos que factores de corte político predominaron tanto en la consideración del electorado como en las circunstancias que rodearon a la frustrada empresa.

La cuestión de la reforma generó una discusión que no se centró únicamente en el contenido de una serie de modificaciones normativas, sino que puso en tela de juicio una forma de hacer política, el futuro del sistema argentino de partidos políticos, el porvenir del justicialismo y del radicalismo, entre otros tópicos de singular trascendencia para la transición democrática en países con graves problemas económicos y en particular para el caso de América Latina. Lo sucedido en la provincia de Buenos Aires desde 1983 resulta interesante para bosquejar los aspectos a que acabamos de hacer alusión.

En 1983, luego de ocho años de gobiernos militares, triunfó la Unión Cívica Radical en los comicios para elegir Presidente y Vicepresidente de la Nación, contrariando la mayoria de los pronósticos electorales que se habían efectuado con anterioridad. La victoria del partido nacional más antiguo de la Argentina también alcanzó a los gobiernos de varias provincias entre las que se destacó la de Buenos Aires, por su peso electoral y por tratarse de un feudo tradicional del justicialismo.

El justicialismo, que habia monopolizado la escena política durante los últimos cuarenta años, fue derrotado fundamentalmente por actitudes y comportamientos de una dirigencia estrechamente vinculada con el viejo peronismo de vocación movimientista y totalizadora, que por aquel entonces la mayoria del pueblo argentino prefirió olvidar.

La derrota trajo aparejada el cuestionamiento de sus cuadros dirigentes y la necesidad de producir cambios en el accionar partidario. Una nueva línea partidaria denominada «Renovación», invocando la necesidad de "cambiarle la cara" al partido, trataría de despojarlo de sus viejos vicios con vistas a disputar la conducción del mismo. La flamante corriente presentó candidatos en las elecciones legislativas de 1985, oportunidad en la cual compitió en muchas provincias con los hombres del justicialismo oficial. El resultado fue muy satisfactorio, ya que pese a que el radicalismo obtuvo la victoria, en el interior del justicialismo triunfaron las listas de la Renovación. En 1987 la tendencia se vio ampliamente confirmada, pues el justicialismo ganó tanto los comicios legislativos nacionales como las gobernaciones de diecisiete provincias sobre veintidós. El triunfo fue capi- 
talizado por la nueva tendencia, que impuso a sus candidatos y como corolario de este nuevo logro obtuvo la conducción del partido (observar los datos de los cuadros 1 y 2 ).

La evolución de la transición democrática puso en evidencia el fracaso electoral tanto de los hombres como del partido que habian conducido la primera etapa de gobierno posterior al proceso militar. Asimismo se ponía de manifiesto una tendencia que luego se iría acentuando hacia la "volatilidad del voto", característica que se va repitiendo en el resto de las nuevas democracias latinoamericanas. La grave crisis por la que atraviesan nuestros países produce el desgaste de sus gobernantes. Frente a la disminución de apoyo popular y de predicamento de la Administración radical, aparecía la figura de Antonio Cafiero, lider indiscutido de la renovación, flamante gobernador de Buenos Aires y conductor del justicialismo, como una suerte de punto de convergencia sobre el cual recaería la responsabilidad de una eventual alternancia en el ejercicio del poder. Además de ello, con la pérdida de quorum propio en la Cámara de Diputados de la Nación, por parte del radicalismo, la carrera de Cafiero hacia la candidatura para la Presidencia de la Nación parecía estar dotada de una fuerza incontenible.

El mérito de la renovación justicialista, que la colocó en un lugar privilegiado de la escena política, residía fundamentalmente en el intento de racionalizar al justicialismo convirtiendo al movimiento - del cual el partido sólo constituía su brazo político- en un partido político. Este proyecto permitía vislumbrar una transformación en el sistema argentino de partidos políticos. Se iría gestando un bipartidismo formado por dos partidos catch all que se repartirian el grueso del electorado con opciones de centro que oscilarian desde la izquierda hasta una derecha moderada. En tal sentido el justicialismo era susceptible de ubicarse dentro de una corriente más cercana a un socialcristianismo, en tanto que era previsible la estructuración de un radicalismo que presentara un perfil más afín con la socialdemocracia. El esquema, muy cercano al sistema de partidos existentes en la mayoria de las democracias europeas desarrolladas, sufriría la prueba de una realidad renuente a colocarse dentro de este tipo de modelos.

Por ello, pese al enfrentamiento Alfonsín-Cafiero ocurrido en el transcurso de la campaña de $1987^{12}$, la evolución posterior iría demostrando un acercamiento bien claro entre ambos, dirigido al diseño de un proyecto político enmarcado en un sistema de partidos con las características del descrito anteriormente.

12 Si bien el enfrentamiento en la provincia de Buenos Aires no se produjo directamente entre ambos dirigentes, el candidato a gobernador por el radicalismo, Juan Manuel Casella, provenia del alfonsinismo. 


\section{CuAdro 1}

\section{LA ELECCIÓN DE DIPUTADOS NACIONALES (1987)}

\begin{tabular}{|c|c|c|}
\hline \multicolumn{3}{|l|}{ TOTALES DE TODO EL PAIS } \\
\hline PARTIDOS & votos & $\%$ \\
\hline Alianza Unidad Socialista & 235.523 & 1,4 \\
\hline Socialista Popular & 13.937 & 0,0 \\
\hline Socialista Democrático ............... & 541 & 0,0 \\
\hline Conservador Popular ................ & 7.293 & 0,0 \\
\hline Del Trabajo y del Pueblo .......... & 23.989 & 0,1 \\
\hline Demócrata Cristiano .................... & 35.929 & 0,2 \\
\hline Demócrata Progresista ............... & 216.932 & 1,3 \\
\hline Federal ............................ & 1.580 & 0,0 \\
\hline Frente Amplio de Liberación ..... & 224.698 & 1,4 \\
\hline Intransigente & 322.611 & 2,0 \\
\hline 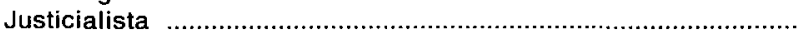 & 6.609 .012 & 41,5 \\
\hline Movimiento al Socialismo ............ & 227.326 & 1,41 \\
\hline Movimiento de Integración y Desarrollo .. & 154.692 & 0,9 \\
\hline Movimiento Línea Popular & 348 & 0,0 \\
\hline Movimiento Patriótico de Liberación & 19.176 & 0,1 \\
\hline Obrero & 42.679 & 0,2 \\
\hline Social Republicano ............................. & 19.038 & 0,1 \\
\hline Unión Cívica Radical .................... & 5.948 .610 & 37,3 \\
\hline UCeDé & 917.499 & 5,7 \\
\hline Unión Popular ............................... & 6.731 & 0,0 \\
\hline Demócrata de Mendoza * ............. & 99.397 & - \\
\hline Alianza Bloquista de San Juan * & 57.929 & - \\
\hline Movimiento Popular Neuquino * . & 61.393 & - \\
\hline Pacto Autonomista Liberal (Corrientes) ${ }^{*} \ldots \ldots \ldots . .$. & 161.526 & - \\
\hline Renovador de Salta ${ }^{*}$ & 68.274 & - \\
\hline
\end{tabular}

* Partidos de distrito. Faltan escrutar 375 mesas.

EVOLUCION DEL CAUDÁ ELECTORAL

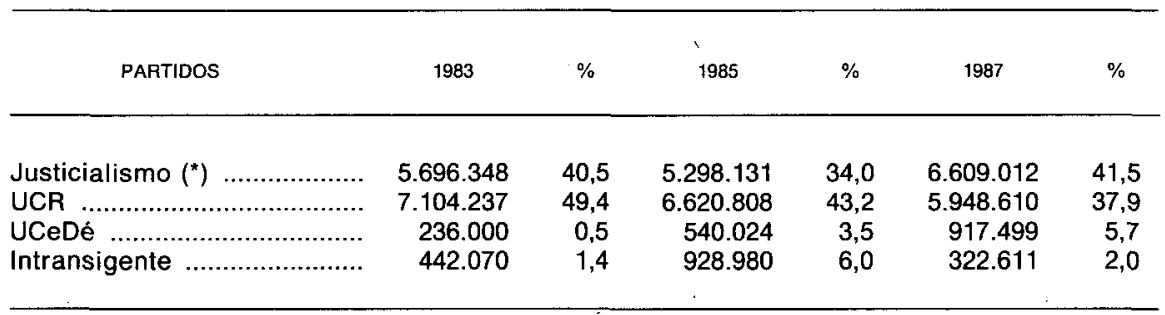

(†) Suma de votos de todos los sectores peronistas.

Fuente: La Nación, 8-IX-87, p. 1. 
EVOLUCIÓN DEL CAUDAL ELECTORAL EN LA PROVINCIA DE BUENOS AIRES

\section{BUENOS AIRES}

\begin{tabular}{|c|c|c|c|c|c|c|c|c|c|c|}
\hline \multirow{3}{*}{ PARTIDO } & \multicolumn{4}{|c|}{1983} & \multirow{2}{*}{\multicolumn{2}{|c|}{$\begin{array}{c}1985 \\
\text { DIPUT. NAC. }\end{array}$}} & \multicolumn{4}{|c|}{1987} \\
\hline & \multicolumn{2}{|c|}{ GOBERNADOR } & \multicolumn{2}{|c|}{ DIPUT. NAC. } & & & \multicolumn{2}{|c|}{ GOBERNADOR } & \multicolumn{2}{|c|}{ DIPUT. NAC. } \\
\hline & Cant. votos & $\%$ & Cant. votos & $\%$ & Cant. votos & $\%$ & Cant. votos & $\%$ & Cant. votos & $\%$ \\
\hline 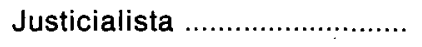 & . 2.141 .732 & 39,7 & 2.239 .629 & 40,4 & 1.549 .744 & 27,0 & 2.799 .250 & 45,6 & 2.702 .324 & 44,0 \\
\hline 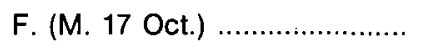 & & & & & 563.269 & 9,8 & 27.602 & 0,4 & 27.080 & 0,4 \\
\hline U.C.P & 2.305 .023 & 52,0 & 2.743 .064 & 49,4 & 2.381 .787 & 41,5 & 2.382 .008 & 38,8 & 2.253 .182 & 36,7 \\
\hline 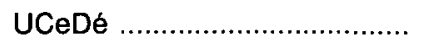 & & & & & & & 290.793 & 4,7 & 374.488 & 6,1 \\
\hline Alianza Laborista .................... & & & & & & & 8.809 & 0,1 & 9.515 & 0,2 \\
\hline Al. del Centro & 19.742 & 0,4 & 62.659 & 1,1 & 229.485 & 4,0 & & & . & \\
\hline 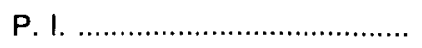 & 224.998 & 4,2 & 209.472 & 3,8 & 574.285 & 10,0 & 173.613 & 2,8 & 194.760 & 3,2 \\
\hline 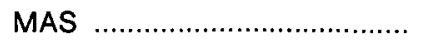 & 31.172 & 0,6 & 30.434 & 0,5 & & & 102.178 & 1,7 & 149.121 & 2,4 \\
\hline MID & 60.933 & 1,1 & 56.987 & 1,0 & & & 37.390 & 0,6 & 41.348 & 0,7 \\
\hline Obrero & 9.549 & 0,2 & 7.804 & 0,1 & 23.178 & 0,4 & 20.353 & 0,3 & 21.227 & 0,3 \\
\hline 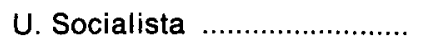 & & & & & 58.849 & 1,0 & 59.029 & 1,0 & 68.652 & 1,1 \\
\hline P.T.P.. & & & & & & & 4.469 & 0,1 & 10.750 & 0,2 \\
\hline
\end{tabular}


Conservador Auton.

MOPALI

FRAL

Al. Patriótica

FREPU

Comunista

Demoprogresista

Federal

Renov. Provinc.

Grupos Liberales

ADS (PDP y PSD)

Conservador Princ.

Fr. Just. Renovador

Social. Pop.

FIP

P.D.C.

Humanista

$\begin{array}{rrrr}22.405 & 0,4 & 25.000 & 0,4 \\ 7.034 & 0,1 & 7.602 & 0,1 \\ 83.586 & 1,4 & 99.563 & 1,6 \\ 10.001 & 0,2 & 10.237 & 0,2\end{array}$

$201.720 \quad 3,5$

$88.805 \quad 1,6$

$\begin{array}{rrrrrr}33.431 & 0,6 & 41.093 & 0,7 & 103.118 & 1,8 \\ 633 & 0,0 & 587 & 0,0 & & \\ & & & & 17.237 & 0,3\end{array}$

$\begin{array}{llll}23.673 & 0,4 & 28.572 & 0,5\end{array}$

$\begin{array}{llll}5.268 & 0,1 & 3.728 & 0,1\end{array}$

$\begin{array}{llll}9.463 & 0,2 & 7.003 & 0,1\end{array}$

$\begin{array}{llll}5.651 & 0.1 & 5.382 & 0.1\end{array}$

$23.118 \quad 0,4 \quad 23.443 \quad 0,4$

\section{TOTAL}

5.396.386

$100 \quad 5.548 .662$

100

13.005

0,2

Fuente: Clarín, 8/9/87, p. 24 
Este proceso de transformación política se vería acompañado de una reforma de la Constitución Nacional que incluiría la modificación de la forma de gobierno ${ }^{13}$. Sobre este punto se llegó a un principio de acuerdo para la instauración de un presidencialismo atenuado, modelo que terminaba con la unipersonalidad del Poder Ejecutivo y estrechaba las relaciones de éste con el Poder Legislativo y, por ende, cambiaría las reglas del juego político.

Curiosamente quien había sido uno de los más destacados responsables de la reubicación del peronismo triunfante en la escena política argentina, perdería la candidatura por su partido a la primera magistratura nacional, menos de un año después de haber asumido la presidencia del mismo.

La elección interna que organizara el partido justicialista para la designación de los candidatos a la presidencia y a la vicepresidencia de la Nación constituyó un hecho inédito en la vida de ese partido. Tradicionalmente la selección de los candidatos era una atribución reservada al conductor del partido. En tal sentido era notorio el papel de Juan Domingo Perón, líder indiscutido del movimiento desde la fundación hasta su muerte, quien a su gusto y placer distribuía premios y castigos entre los dirigentes del movimiento, sin que nadie compartiera su omnímoda actuación. De esa práctica centralizadora se pasaba a una forma abierta y pluralista donde cada una de las líneas internas podía disputar, en un pie de igualdad, las preferencias de un amplio electorado formado por los afiliados del partido.

Este escenario, caracterizado por las nuevas e inéditas reglas de juego, serviría de telón de fondo para el enfrentamiento entre dos hombres que curiosamente provenian de la renovación: Antonio Cafiero y Carlos Menem. Claro que este último lo hacia desafiando a la estructura partidaria, para lo cual reclutó a sus cuadros entre aquellas figuras y grupos que habian quedado heridos por las transformaciones de que había sido objeto el justicialismo. Su apoyo provino esencialmente del viejo sindicalismo y de dirigentes que habian quedado desplazados de la conducción partidaria. Su prédica se dirigió directamente al electorado tradicional del justicialismo apoyándose en un discurso populista que retrotrajo el mensaje del partido a los postulados y símbolos que habían acompañado a las primeras épocas del movimiento.

Por asombroso que parezca fue esta última opción la que predominó el 9 de julio de $1988^{14}$, contrariando todos los pronósticos preelectorales

13 Para una mayor información sobre la naturaleza de una de las propuestas más comentadas que se originó desde el gobierno, consultar: Reforma constitucional. Dictamen preliminar del Consejo para la consolidación de la Democracia, EUDEBA, Buenos Aires 1986, y Segundo dictamen del Consejo para la consolidación de la Democracia, EUDEBA, Buenos Aires 1987.

14 Los comicios internos arrojaron los siguientes resultados: Menem - Duhalde, 833.353 votos; Cafiero - De La Sota, 711.596 votos. 
que se fueron realizando durante la campaña. Nuevamente la ciudadanía, al igual que en 1983 y en 1987, sorprendía a sociólogos y a encuestadores. La tradición política pendular de la Argentina llevó las preferencias de la ciudadanía hacia las antípodas. A partir de allí la corriente alfonsinista del radicalismo, que ya se había visto forzada a ceder la candidatura a la presidencia para el año 1989 a Eduardo Angeloz —representante de una de las líneas internas que enfrenta a Renovación y Cambio ${ }^{15}$-, se convierte de algún modo en una suerte de aliada del cafierismo - es decir, de los sectores de la renovación peronista más cercanos al gobernador de Buenos Aires-.

Dadas estas circunstancias, el intento de reforma de la Constitución de la provincia de Buenos Aires importaba, más allá de los propósitos que inspiraron a sus protagonistas, el deseo de consolidar en un importante bastión, como es ese estado provincial, el modelo que había resultado perdedor a nivel nacional.

La realidad ubicó tanto a Menem como a Angeloz en posiciones ambiguas. Por una parte se veian obligados a ratificar lo que habian decidido los órganos directivos de sus respectivos partidos. Desconocer tales decisiones hubiera significado rebelarse abiertamente contra los principios esenciales de la vida partidaria. Asimismo, una actitud contraria no se hubiera compatibilizado con las reformas que ambos habían motorizado pocos años antes en sus respectivas provincias. Menem, cuando era gobernador de La Rioja, y Angeloz, en su calidad de primer mandatario de Córdoba. Pero por otro lado apoyar abiertamente la reforma bonaerense importaba en el plano político fortalecer a las corrientes rivales en el interior de cada uno de los dos grandes partidos.

El Presidente decide, luego de ciertos titubeos, apoyar de manera explícita a la reforma pocos días antes de los comicios. Ello, a pesar de que el triunfo de la afirmativa implicaba la posibilidad de reelección como gobernador ${ }^{16}$ de su enemigo interno y presidente del justicialismo. Angeloz, por su parte, frente a la requisitoria periodistica, expresa su posición favorable a la modificación pero contraria al procedimiento elegido para su efectivización.

Poco tiempo antes de que el plebiscito tuviese lugar, la situación política en relación con la reforma parecía muy sencilla. Ello en la medida que la misma había sido impulsada y aprobada en la legislatura provincial por los dos grandes partidos nacionales, quienes en 1989 habian conquistado conjuntamente alrededor del 80 por 100 del caudal electoral. En consecuencia se descontaba una clara victoria de la posición favorable a la modificación de la Constitución.

15 Renovación y Cambio es una corriente interna del radicalismo, que surge a principios de la década de los setenta, liderada por Raúl Alfonsin, como movimiento opositor a la tradicional Línea Nacional.

16 Artículo $110 \mathrm{del}$ proyecto de reforma. 
Sin embargo, la particular situación política por la que atraviesa la Argentina no permitía la realización de evaluaciones tan simplistas. Lo que iba aconteciendo planteaba serias incógnitas para todo observador cuidadoso, por ejemplo, resultaba curioso que dentro mismo de aquellos partidos que oficialmente habían impulsado la reforma, se fueran generando corrientes opuestas a ella. Podemos asegurar que quienes presentaban una posición afín con esa tendencia, o bien decidieron no movilizar a sus huestes a favor de la reforma o se pronunciaron abiertamente en contra de la misma.

Resulta interesante observar cómo se concretó el alineamiento de fuerzas sociales y políticas en torno a las reformas. A favor de ella se pronunciaron además de Cafiero y de Alfonsín, los principales dirigentes sindicales -aun aquellos que se consideran menemistas - y la mayor parte de los partidos que en 1989 integraron el Frejupo. Esta última fue la alianza que se formó en torno al partido justicialista en 1989 y que tuvo por candidato a Menem. Se trata de partidos que en su mayoría son de centroizquierda y que hoy se sienten defraudados tanto por el hoy Presidente de la República como por su programa de gobierno.

A favor del NO se agruparon partidos de las más variadas tendencias. A la derecha, la Unión de Centro Democrático - principal aliado postelectoral de Menem-, el Movimiento de Integración y Desarrollo y la Democracia Progresista. Ya en la extrema derecha manifestaron su oposición el ex teniente coronel Aldo Rico, máximo cabecilla de los levantamientos acaecidos durante el gobierno de Alfonsín, y el general Bussi, figura vinculada estrechamente con los gobiernos de facto del período 1976-83, quien actualmente lidera el Partido Fuerza Republicana. Curiosamente esta posición también fue compartida por el Movimiento al Socialismo y por el Partido Obrero, ambos de orientación trotskista.

Acompañaron a estos circunstanciales aliados, la Sociedad Rural Argentina, la Confederación de Asociaciones Rurales de Buenos Aires y La Pampa y la Cámara Argentina de Comercio, para citar sólo a algunas de las entidades más importantes del campo y del comercio que optaron por el NO.

La argumentación esgrimida por los partidarios del NO puede ser resumida del siguiente modo:

- Tanto desde la derecha como desde la izquierda se aconsejó al electorado a pronunciarse por la negativa como una muestra de rechazo a la administración de Cafiero, para quien se solicitaba un «voto castigo». Además se expresó que el motivo real de la reforma consistía precisamente en la posibilidad de que el gobernador pudiese presentarse a las elecciones del año próximo y de ese modo asegurarse su reelección. El Movimiento a) Socialismo, junto a los otros aliados de izquierda, agregaban a estos argumentos la necesidad de demostrar el repudio a la política económica 
nacional del Gobierno de Menem, posición que obviamente no compartió la derecha.

- Se invocó la inconstitucionalidad del procedimiento elegido para reformar la Constitución, ya que se consideró que lo apropiado hubiese sido convocar a una Convención Provincial Constituyente.

- Se aludió a la inoportunidad de la reforma dada la situación económica crítica por la que atravesaba el país, ya que el remedio constitucional sería totalmente inoperante para enfrentarla. Por el contrario, se consideró que un proceso electoral en esas condiciones importaba agravar con mayores erogaciones el cuadro general de la nación.

- Por último, es de destacar que fueron muy pocas las consideraciones que se hicieron sobre el contenido de las reformas propuestas. Al respecto se trató de infundir miedo a la población poniendo el acento sobre las peligrosas consecuencias que tendrían las reformas, en particular sobre el derecho de propiedad. En esa misma línea argumental se calificó de anticuado a un proyecto que hablaba de la función social de la propiedad, contrariando las ideas de apertura, competencia y libre empresa que estarían cobrando auge en el resto del mundo.

Por su parte, la campaña impulsada por los partidarios de Sí se vio afectada por un exagerado optimismo inicial. Se supuso que por el hecho de contar con el apoyo de los dos mayores partidos nacionales la victoria estaba descontada. Por lo tanto sólo se inició la campaña para hacer frente a la oposición cuando se tomó conciencia de que la prédica de esta última empezaba a influir fuertemente en el ánimo del electorado. Ante este cuadro de situación los sostenedores del SI adoptaron una posición defensiva, intentando rebatir los cuestionamientos provenientes del campo opuesto, con una poco eficaz y esclarecedora campañá publicitaria.

\section{CONSIDERACIONES FINALES}

El fallido intento de reforma de la Constitución bonaerense marca un alto en el ciclo constituyente provincial que dio comienzo en 1985. En esta oportunidad el procedimiento elegido para proceder a la modificación constitucional fue diferente del que se había empleado con anterioridad en el resto de las provincias. Ello en razón de que en estas últimas se había recurrido al sistema de Convención Constituyente. Una primera evaluación sobre la modalidad plebiscitaria nos permite inclinarnos a favor de su utilización. Puesto que dadas las particulares características imperantes en 
la Argentina, en cuanto a sistema electoral y disciplina partidaria en los cuerpos colegiados, la participación ciudadana y su grado de compromiso con el proceso reformador fueron mucho mayores en Buenos Aires que en las otras provincias. Pensamos que la diferencia se debió fundamentalmente al hecho de que la reforma debió ser resuelta en última instancia por la ciudadanía.

Sin embargo, no obstante el interés que despertó la consulta sobre el electorado, entre los motivos del NO pesaron cuestiones que mayoritariamente nada tuvieron que ver con el contenido de la propuesta de modificación. Al respecto distintas encuestas pusieron de manifiesto que alrededor del 72 por 100 de los votantes poseía un profundo desconocimiento acerca de las propuestas contenidas en el proyecto de reforma ${ }^{17}$. El voto negativo estuvo impulsado: a) por argumentos de tipo político coyuntural manejados desde la oposición, que apuntaban contra la figura del gobernador y no contra el texto en sí mismo; b) por un sentimiento de repudio a la política económica nacional, caracterizada por la dureza de los «ajustes» y el descenso del nivel de vida de la gran mayoría de la población; y c) como expresión de rechazo a algunos puntos de la reforma, haciéndose eco de ciertos argumentos de la oposición que había logrado infundir temor en vastos sectores del electorado. En el transcurso de la campaña se pusieron en juego principalmente sentimientos y no ideas ${ }^{18}$.

El resultado del plebiscito demuestra en gran medida el cansancio de la ciudadanía, la que acuciada por problemas que en amplios sectores hacen a la mera subsistencia, no se interesa por las cuestiones de fondo. Cuestiones que en muchas oportunidades percibe como el fruto de acuerdos entre cúpulas partidarias para conseguir la permanencia en el poder. Todo este estado de cosas se combina con un hartazgo de los ciudadanos hacia la dirigencia política. Los hombres del poder son considerados, por una amplia mayoria, como corruptos, ambiciosos y alejados de los problemas de la gente común y, en el mejor de los casos, como inoperantes.

La magnitud del voto por el NO al superar los dos tercios del electorado está señalando un grave síntoma de disconformidad de parte de una ciudadanía que por primera vez decide terminar con la hegemonia de los

17 La Nación, 6 de agosto de 1989, p. 11, Buenos Aires.

18 Fueron pocos los dirigentes que ubicarón la discusión en un plano ideológico. Una excepción en tal sentido la constituyó A. Alsogaray, presidente de la Unión de Centro Democrático y asesor presidencial, quien manifestó que "los derrotados fueron los dirigentes de la socialdemocracia en Argentina, Raúl Alfonsín y Antonio Cafiero, principales inspiradores de esta reforma constitucional de contenido socializante" (La Nación, 6 de agosto de 1990, p. 11, Buenos Aires). Independientemente de la opinión que merezca esta interpretación, ella eleva el debate al plano de las ideas, dejando de lado razonamientos superficiales de corte meramente electoralista. 
dos grandes partidos tradicionales: justicialismo y radicalismo. Ya que lejos de obedecer a la voz de las conducciones de ambos, expresa una actitud contraria a las mismas. Este fenómeno ya tuvo sus antecedentes en comicios provinciales y municipales. Son los casos de Tucumán y Chaco, donde han triunfado los candidatos de nuevos partidos provinciales, hombres ligados al último gobierno militar. $Y$ también es lo que se produjo el año pasado en las ciudades de Rosario y Santa $\mathrm{Fe}$, en las cuales triunfó el socialismo y la democracia progresista, respectivamente.

La situación responde a problemas estructurales y ha impedido que el triunfo del NO pueda ser capitalizado por alguno de los heterogéneos sectores que se opusieron a la reforma. Todo esto muestra la vulnerabilidad creciente de la dirigencia en su conjunto, no sólo de la política, lo que por otra parte es corroborado a diario en numerosas encuestas. En lo que hace a lo estrictamente político, desde diferentes sectores se pide la reforma del sistema electoral. Surgen innumerables propuestas con la pretensión de sustituir a la representación proporcional combinada con la lista cerrada y bloqueada, tal el régimen vigente y que estaria en la base de todos los males. Más allá de la pretensión reformista que sin lugar a dudas puede ayudar a solucionar algunos problemas, consideramos que depositar todas las ilusiones en un mecanismo de tipo legal es una manera de minimizar la magnitud de los problemas de administración y de legitimidad que están acosando a nuestra joven democracia.

Por último, pensamos que el fracaso de la reforma de la Ley Fundamental bonaerense se inscribe dentro de una larga lista de acontecimientos que han sucedido en casi todas las nuevas democracias latinoamericanas. Entre ellos podemos destacar la casi desaparición de los partidos tradicionales brasileños, luego de las últimas elecciones presidenciales, o el fenómeno Fujimori en el Perú, para sólo citar los dos ejemplos más colosales. Todos ellos, a nuestro entender, constituyen meros síntomas de una realidad muy preocupante en la cual intervienen diversos factores, pero entre ellos estimamos que el más grave consiste en la dificultad de asegurar el imperio de la libertad en lugares donde resulta casi imposible lograr un mínimo de igualdad o al menos conseguir que se achiquen las distancias entre los distintos sectores que componen la sociedad. 